everyday life as well as sexual activity provides many opportunities via breaches in skin and mucous membranes.

N R GRIST

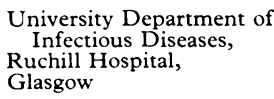

***our expert writes: "Professor Grist is, of course, correct in pointing out that the term 'parenteral' in the strictest sense means introduction via any route other than the digestive tract. It is, however, in common usage restricted to the subcutaneous, intramuscular, and intravenous routes; hence the opposite becomes 'non-parenteral.' However, in a recent series of patients with acute hepatitis B studied in London homosexual contact seemed to be the most common source of exposure. In these instances perhaps the term 'enteral' would have been appropriate." -ED, $B M \mathcal{F}$.

\section{Propranolol absorption in Crohn's disease and coeliac disease}

SIR,-We were interested to read of the findings of $\mathrm{Dr} R \mathrm{E}$ Schneider and others (2 October, $p$ 794) that propranolol was absorbed better in Crohn's disease at 1-6 h after ingestion and in treated coeliacs at $\frac{1}{2} \mathrm{~h}$ after ingestion than in healthy volunteers, though the significance of their observations was not discussed. In 1959 Hogben et al postulated the presence of a layer of hydrogen ions (acid microclimate) on the luminal surface of the proximal jejunum to explain the unexpectedly enhanced absorption of certain drugs which were also weak acids. Thus the absorption of substances with a low $\mathrm{pKa}$ will be facilitated by the presence of a jejunal acid microclimate. This microclimate has been proposed as a means of facilitating the non-ionic passive absorption of folic acid, $-50^{\circ}{ }_{0}$ of which is present as neutral species at $\mathrm{pH} 3 \cdot 5$. We have shown that the acid microclimate is present in the normal human jejunum. ${ }^{3}$ Also further work has demonstrated a defective microclimate in Crohn's disease ${ }^{4}$ and in untreated coeliac disease, "two diseases often associated with folic acid deficiency. Conversely, the absorption of drugs with a high $\mathrm{pKa}$ will be facilitated by a loss of the acid microclimate and it has been shown" that quinine (pKa 8.4) is better absorbed in "partial villous atrophy" than in normals. The $\mathrm{pKa}$ of propranolol is also high (9.45), which would explain its enhanced absorption in Crohn's disease. The near-normal absorption of propranolol in treated coeliacs is consistent with the recovery of the acid microclimate seen in coeliacs on a gluten-free diet." However, the better absorption of propranolol at $\frac{1}{2} \mathrm{~h}$ in treated coeliacs compared with the controls indicated that the acid microclimate in these patients had not fully recovered. Therefore it would have been useful to have some details of the jejunal histology in these treated coeliacs. Also it would be of interest to know the absorption of propranolol in untreated coeliacs, which we suspect would be enhanced.

Further evidence for the role of the acid microclimate in explaining these results is provided by the relatively low serum levels seen in the controls after a relatively large oral dose of propranolol $(40 \mathrm{mg})$, indicating that propranolol absorption in normal subjects is not facilitated easily. Also the absorption of propranolol in the controls was maximal at $2 \mathrm{~h}$ after ingestion, which suggests that propranolol absorption occurs more distally than in the proximal jejunum, since the microclimate becomes progressively less acid towards the distal jejunum and ileum. ${ }^{3}$

Finally, the finding of two groups of patients with Crohn's disease with respect to propranolol absorption is consistent with our own findings that there are two groups of such patients with respect to proximal jejunal acid microclimate -a higher acidity and a lower acidity groupboth significantly less acid than controls. ${ }^{4}$

B T COOPER W TREVOR COOKE

Nutritional and Intestinal Unit,

General Hospital, Birmingham

$M$ L LUCAS

JOHN A BLAIR

Department of Chemistry

University of Aston in Birmingham,

Birmingham

${ }^{1}$ Hogben, C, et al, fournal of Pharmacology and Experimental Therapeutics, 1959, 125,275 , 27 .
B Bair, $\mathrm{J}$ A, and Matty, A, Clinics in Gastroenterology,

$1974,3,183$.
Lucas, M L, et al, Biochemical Society Transactions, 1976, 4, 154 .

Cooper, B T, et al. Submitted for publication.

Lucas, $M$ L, et al. Submitted for publication. Forschung, 1973, 23, 583 .

\section{Sedatives and driving}

SIR,-Parliamentary concern with the hazards of driving a motor vehicle extend now to proposals to lower the legal limit for blood alcohol while driving and to make compulsory the wearing of seat belts. There appears to be little concern about the number of motorists whose state of alertness and quality of judgment are impaired by medication.

If exacting standards are to be applied to the drinker of alcohol, then surely these same standards should be applied to the consumers of sedatives, anxiolytics, antidepressants, and antihistamines if not, indeed, a few other drugs also. I endeavour to advise my patients not to drive a car if my prescription is likely to interfere with their cerebration, but I, and most doctors, know that this advice is not heeded.

Is it possible to establish that patients taking these drugs do indeed have more accidents than others? Should our profession take a firmer line on the subject? The police appear not to have pursued this cause of accidents and will shortly lose the opportunity to analyse a blood sample when the new breathalysers are introduced.

Abergavenny, Gwent

John Plumb

\section{Detection of paraquat in urine}

SIR,-Paraquat can be readily detected in urine by reducing it to a blue radical ion with sodium dithionite under alkaline conditions. In a previous letter ( 3 January, $p$ 42) the need for a simple ward test for the early detection of paraquat was emphasised and a suitable procedure was described. This test has now been simplified even further by formulating the reagents in capsule form. Sodium hydroxide is replaced as the alkaline agent by a mixture of sodium bicarbonate and $\mathrm{pH} 9$ buffer powder. The buffer powder is incorporated to ensure that an alkaline $\mathrm{pH}$ is achieved, since experiment showed that for some acidic urines sodium bicarbonate alone did not suffice. For convenience the following quantities of the reagents are thoroughly mixed and packed into 1-g gelatin capsules (gauge 0 ): sodium dithionite, $10 \mathrm{~g}$; pH 9 buffer powder (EIL, Chertsey, Surrey), $6 \mathrm{~g}$; sodium bicarbonate, $25 \mathrm{~g}$.

The test is performed by breaking open the capsule, tipping the contents into $10 \mathrm{ml}$ of urine, and shaking gently until dissolved. A green or blue colour is indicative of paraquat and by preparing aqueous standard solutions of paraquat the test may be made semiquantitative. The capsules are stored at room temperature in a screw-capped container and remain viable for at least six months.

B WIDDOP

Poisons Unit,

Guy's Hospital

London SE1

\section{White coat}

SIR,-For your article "New kinds of doctors" (9 October, p 862) why choose a GP who wears a white coat? He says, "We should help our students to become doctors of a quite different kind from their teachers," but they all wear this me-doctor, you-patient uniform to satisfy their egos. Most GPs, I suggest, would consider it idiotic to wear a "protecting" garment.

DAVID VICARY

Eye,
Suffolk

\section{Not cricket}

SIR,-To describe the greatest cricketer the world has ever known as "notorious" (23 October, p 991) passes all understandingeven when he is so described by a Scot.

J P SPARKS

The Sanatorium,
Rugby School

\section{The hospitals we need}

SIR,-I was extremely interested to read Dr A L de Silva's letter (23 October, $p$ 1015). He is asking a question which I had prepared in a more easily measurable field-namely, within the constraints under which we work, are our patterns of practice, and particularly hospital practice, geared to give doctors working in the service the best scope for their expertise and skills? Also are these factors geared to giving the best service to patients within the same constraints? The parallel question is, within the constraints of the NHS, to which so many of us rightly object, is there not room for a little market research with possible benefits all round, to patients, to the profession, and to the taxpayer?

I am suggesting elsewhere, and Dr de Silva has beaten me to the draw, that one field where alternative patterns of practice might be 